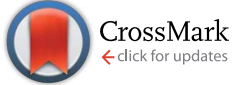

Cite this: RSC Adv., 2017, 7, 14152

Received 14th January 2017

Accepted 24th February 2017

DOI: $10.1039 / \mathrm{c} 7 \mathrm{ra00590c}$

rsc.li/rsc-advances

\section{Nickel nanoparticles supported on nitrogen-doped honeycomb-like carbon frameworks for effective methanol oxidation $\uparrow$}

\author{
Juan Wang, ${ }^{a}$ Qi Zhao, ${ }^{a}$ Hongshuai Hou, ${ }^{b}$ Yifei Wu, ${ }^{a}$ Weizhen $\mathrm{Yu}{ }^{\mathrm{a}}$ Xiaobo Ji ${ }^{\star \mathrm{b}}$ \\ and Lidong Shao*a
}

In this work, nitrogen-doped honeycomb-like carbon framework (CNFs) is synthesized by a low-cost and scalable method. Ni nanoparticles are then supported on CNFs (CNFs-Ni) as a catalyst for methanol oxidation. In addition to the enhanced mass activity, both the onset and oxidation peak potentials of CNFs-Ni for methanol oxidation shift negatively in comparison to its non-doped counterpart, CFs-Ni. We propose that the small particle size, uniform dispersion, and electronic effect arising from the electron interactions between CNFs and Ni contribute to the improved electrocatalytic performance.

\section{Introduction}

Over the past several decades, significant progress has been made in developing carbon materials for catalytic and electrocatalytic applications. ${ }^{\mathbf{1 , 2}}$ Carbon black has been widely used supporting material in electrocatalytic reactions. However, its agglomeration property reduces its active oxidant utilization and increases the transportation resistance in catalysis process. ${ }^{3}$ One or two dimensional graphitized carbon materials, such as carbon nanotubes, graphene have been used as supporting materials with unique electronic and chemical properties. $^{4,5}$ For example, Gong et al. used oxygen functionalized carbon nanotubes supported $\mathrm{NiO} / \mathrm{Ni}$ heterostructures for hydrogen generation from water electrolysis. And due to the interaction between the oxygen functionalized CNTs and nickel precursors, the reduction of nickel species into larger aggregated nanoparticles and less reactive pure phase nickel were impeded during the thermal treatment process ${ }^{6}$ which contributed to the excellent catalytic performance.

Recently, porous carbon networks with high specific surface area, good conductivity, and additional ion diffusion channels have been extensively investigated as catalysts or supports. Zhang et al. used a porous carbon framework with a dense network for interdispersing $\mathrm{MnO}$ nanoparticles, with the obtained composite displaying an enhanced capability and cycling properties. $^{7}$ Active Pd were supported on hierarchical porous

${ }^{a}$ Shanghai Key Laboratory of Materials Protection and Advanced Materials in Electric Power, Shanghai University of Electric Power, Shanghai 200090, PR China. E-mail: lidong.shao@shiep.edu.cn

${ }^{b}$ College of Chemistry and Chemical Engineering, Central South University, Changsha, 410083, PR China.E-mail: xji@csu.edu.cn

† Electronic supplementary information (ESI) available: XRD, Nyquist plots. See DOI: $10.1039 / \mathrm{c} 7 \mathrm{ra00590c}$ carbon which derived from a zeolitic imidazolate framework (ZIF-8), and employed in methanol oxidation, excellent activity and stability were obtained. ${ }^{8}$

Nitrogen-doped carbon materials have been the subject of much investigation for catalytic reactions, mainly due to the abundance and accessibility of the required raw materials. In addition, the incorporation of nitrogen atoms into the carbon nanostructures resulted the tailoring of the surface chemical and electronic properties of carbon materials. After nitrogen doping, the carbon nanotubes displayed basic properties are beneficial for solid base catalysis. ${ }^{9}$ Nitrogen doping can facilitate the adsorption of oxygen and decomposition of hydroperoxide in oxygen reduction reactions. ${ }^{10}$ Sheng et al. reported an excellent oxygen reduction activity of nitrogen doped graphene, and the electronic effect arising from the interactions between the doped nitrogen atoms and the neighbored carbon atoms contributed to the catalytic activity. ${ }^{\mathbf{1 1}}$

The lone electron pairs of nitrogen atoms can delocalise in the conjugated system of the $\mathrm{sp}^{2}$-hybridised carbon frameworks, and the N-doped carbon structure has already been employed to enhance the catalytic activities in electrochemical reactions. ${ }^{12}$ Pt nanoparticles modified nitrogen doped porous carbon nanocubes were prepared for methanol oxidation, and the good electrocatalytic performances were arising from the uniform particle dispersion, high surface area, and the interaction between the support and Pt nanoparticles. ${ }^{13}$ High nitrogen content doped mesoporous carbon supported Pd nanoparticles were used for biomass refining, achieving excellent catalytic conversion and selectivity. ${ }^{\mathbf{1 4}}$ Nowadays, the development of low-cost, scalable, economically attractive and sustainable carbon materials based on renewable and highly abundant resources is extremely important. ${ }^{15}$ As low-cost and non-noble metal materials, nickel based catalysts with good surface catalytic oxidation activities in alkaline electrolyte have 
been the subject of much investigation. ${ }^{\mathbf{1 6 , 1 7}}$ Kannan et al. prepared $\mathrm{NiMoO}_{4}$ nanorods with graphene by a facile hydrothermal process for methanol oxidation, and arising from the unique one dimensional structure and well distributed carbon, enhanced catalytic activity and high stability were obtained. ${ }^{\mathbf{1 8}}$ $\mathrm{Co}_{3} \mathrm{O}_{4} / \mathrm{NiO}$ nanowire arrays with hierarchically porous core and branch nanoflakes shell was prepared for methanol oxidation and the electrode showed lower over-potential, high reactivity and stability in the electrocatalytic tests which was attributed to the synergistic effect and core-shell structure. ${ }^{19}$

Herein, a feasible, simplified and productive synthesis procedure to produce nitrogen-doped carbon frameworks (CNFs) with porous structure and morphology is proposed. And the nickel nanoparticles with small particle size and narrow size distribution and were supported on the CNFs. Methanol was chosen as the molecular target to investigate the electrocatalytic properties.

\section{Experimental}

\section{Materials and methods}

Potassium hydroxide ( $\geq 99.0 \%$ ), nickel(II)nitrate hexahydrate $(\geq 98.0 \%)$, sodium hydroxide $(\geq 97.0 \%)$, acetone $(\geq 99.5 \%), \mathrm{HCl}$ (35-37 wt\%), Nafion solution (5 wt\%), and methanol ( $\geq 95 \%)$ were bought from Aldrich Chemical Co. (USA). A JEOL JSM$7400 \mathrm{~F}$ instrument with an acceleration voltage of $3 \mathrm{kV}$ was used for scanning electron microscopy (SEM) characterization.

A Bruker DAVINCI D8 ADVANCE diffractometer with $\mathrm{Cu} \mathrm{K}_{\alpha}$ radiation $(\lambda=0.15406 \mathrm{~nm}$ ) was used for X-ray diffraction (XRD) characterization. X-ray photoelectron spectroscopy (XPS) characterization was conducted on a Thermos ESCALAB 250 spectrometer with an $\mathrm{Al} \mathrm{K} \alpha$ radiation source (passing energy: $30 \mathrm{eV}$ ). All binding energies were calibrated using the $\mathrm{C} 1 \mathrm{~s}$ hydrocarbon peak at $284.60 \mathrm{eV}$. Inductively coupled plasma optical emission spectrometry (ICP-OES, PerkinElmer Optima 8000) was used for the Ni content measurement of samples. Transmission electron microscopy (TEM) and scanning transmission electron microscopy (STEM) characterizations was performed on a JEOL JEM-2100 High Resolution Transmission Electron Microscopy (HRTEM) instrument with $200 \mathrm{kV}$ operation voltage. A potentiostat (SP-300, BioLogic Science Instruments, France) was used for investigating the electrochemical properties of catalysts. All electrochemical measurements were conducted in a threeelectrode cell, with Pt wire as counter electrode, a glass carbon (GC) disk (3 mm diameter) as a working electrode and $\mathrm{Hg} / \mathrm{HgO}$ as a reference electrode. The working electrode was prepared by dispersing $2 \mathrm{mg}$ of the as-prepared catalyst in a mixture of $200 \mu \mathrm{L}$ deionized water, $800 \mu \mathrm{L}$ ethanol, and $120 \mu \mathrm{L}$ of $5 \mathrm{wt} \%$ Nafion solution. And then, sonicated the mixture for about $20 \mathrm{~min}$ to form homogeneous ink, and $5.6 \mu \mathrm{L}$ of the ink was placed on a GC disk electrode, which was then dried gently in air and ready for use.

\section{Synthetic procedures}

Synthesis of CFs. Sodium hydroxide ( $8 \mathrm{~g}$ ) was mixed with acetone $(40 \mathrm{~mL})$ under vigorous magnetic stirring for $1 \mathrm{~h}$, and

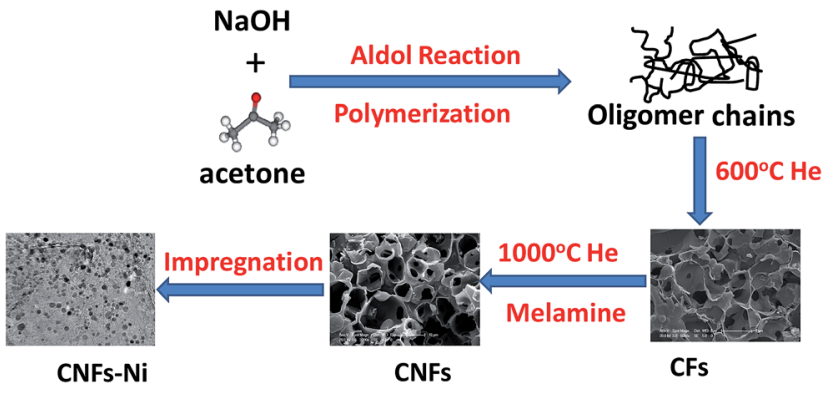

Fig. 1 Schematic design and preparation process of the CNFs-Ni catalyst.

the mixture was kept at ambient conditions. After $120 \mathrm{~h}$, the colour of the mixture changed to dark brown, and the liquid phase composites were transformed into solid products, which were calcined at $600{ }^{\circ} \mathrm{C}$ for $2 \mathrm{~h}$ in a He atmosphere at a heating rate of $10{ }^{\circ} \mathrm{C} \mathrm{min}^{-1}$ and cool to room temperature, after that, washed with diluted $\mathrm{HCl}$ solution $(1 \mathrm{M}$ ) and distilled water sever times, and then, filtered and dried at $100{ }^{\circ} \mathrm{C}$ for $12 \mathrm{~h}$ to obtained CFs. $^{20}$

Synthesis of CNFs. Nitrogen-doped CFs was prepared by simple thermal treatment: a mixture of CFs $(200 \mathrm{mg})$ and melamine (1051 $\mathrm{mg}$ ) was placed in the centre of a corundum tube kept under a flow of He. When the furnace centre reached a temperature of $1000{ }^{\circ} \mathrm{C}$, the mixture was annealed for $60 \mathrm{~min}$ at this temperature, and the sample was cooled to room temperature under $\mathrm{He}$ atmosphere.

Synthesis of CNFs-Ni and CFs-Ni. Impregnation-reduction method was used to prepare CNFs-Ni and CFs-Ni catalysts. $\mathrm{Ni}\left(\mathrm{NO}_{3}\right)_{2} \cdot 6 \mathrm{H}_{2} \mathrm{O}(32.4 \mathrm{mg})$ and CNFs $(158 \mathrm{mg})$ were dispersed in ethanol. The impregnated material was appropriately hydrolysed to crystallise the precursors, which were annealed in a tube furnace at $310{ }^{\circ} \mathrm{C}$ for $2 \mathrm{~h}$ under $\mathrm{He}$, followed by annealing at $500{ }^{\circ} \mathrm{C}$ for $2 \mathrm{~h}$ under $\mathrm{He} / \mathrm{H}_{2}$. Finally, the sample was cooled to room temperature under $\mathrm{He}$, and the products were taken out of the corundum tube. The CFs-Ni catalyst was synthesised in a similar way, by passing the nitrogen doping procedure. Fig. 1 shows the schematic preparation of CNFs-Ni.

\section{Results and discussion}

\section{Structural characteristics}

The morphology and microstructure of CNFs were characterised by SEM. Fig. 2 shows honeycomb-like porous frameworks composed of interconnected and well-arranged nanosheets, at low and high magnifications. The SEM and TEM images show porous carbon frameworks with different pore diameters composed of micropores and mesopores. It is generally considered that the large pore sizes and multi-charge transfer channels provided by the carbon frameworks facilitate diffusion of reactants to the electrocatalytic active sites. More specifically, microporous carbons with large specific surface areas contributed to the electrocatalytic activities; ${ }^{21-23}$ a porous structure with large mesopores instead of micropores is beneficial for contact with reactants, and reduce the mass-transport limitations. ${ }^{24-26}$ 

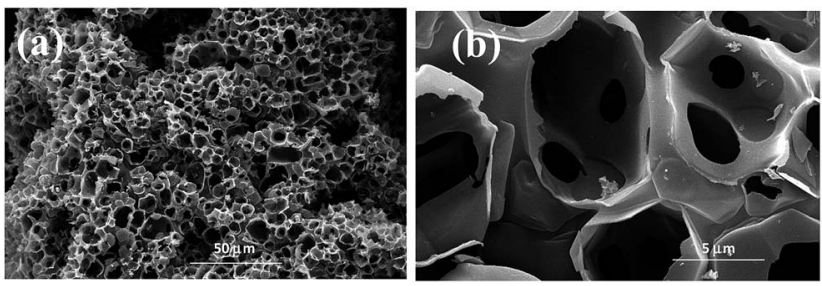

Fig. 2 SEM images of CNFs at (a) low and (b) high magnification

TEM images reveal that graphene-like thin-layer CNFs and CFs with porous structures are uniformly covered with nanoparticles. The catalyst particle sizes were estimated from the TEM images, with the size distribution histograms shown in Fig. 3a-c. HR-TEM imaging results for CNFs-Ni are shown in Fig. 3d, and the Ni lattice spacing was $0.2 \mathrm{~nm}$ which corresponds to the 111 crystal plane. The particle size range of CNFsNi was 2-12 nm, with an average of $6.45 \mathrm{~nm}$, while $\mathrm{CF}-\mathrm{Ni}$ particles were $4-14 \mathrm{~nm}$ in size (average of $8.01 \mathrm{~nm}$ ).

The smaller particle size and narrow size distributions of CNFs-Ni might originate from the nitrogen doping. After nitrogen doping, smaller particle size and narrow size distributions were obtained. Nitrogen species on the CNFs provides induced defects in the framework, in addition, nucleation is enhanced after nitrogen doping, thus, more nucleation sites generate for particle growth. The surface defects and electronic effects arising from the nitrogen doping, induced the interactions between nanoparticles and CNFs, thus, promotes the anchoring of nanoparticles. ${ }^{27}$ Better hydrophilicity also obtained by nitrogen doping into the carbon materials. ${ }^{28}$ During the impregnation process, facilitate the solvated and charged $\mathrm{Ni}^{2+}$ ions to the CNFs surface, thus better dispersion can obtained and avoid the Ni nanoparticles aggregates into larger ones. $^{27}$

STEM imaging and energy dispersive X-ray spectroscopy (EDX) mapping results for CNFs-Ni are shown in Fig. 4, indicating a homogeneous distribution of $\mathrm{C}, \mathrm{N}, \mathrm{O}$, and $\mathrm{Ni}$ in the catalyst. Fig. S1 (ESI $\dagger$ ) shows the XRD patterns of CFs-Ni and
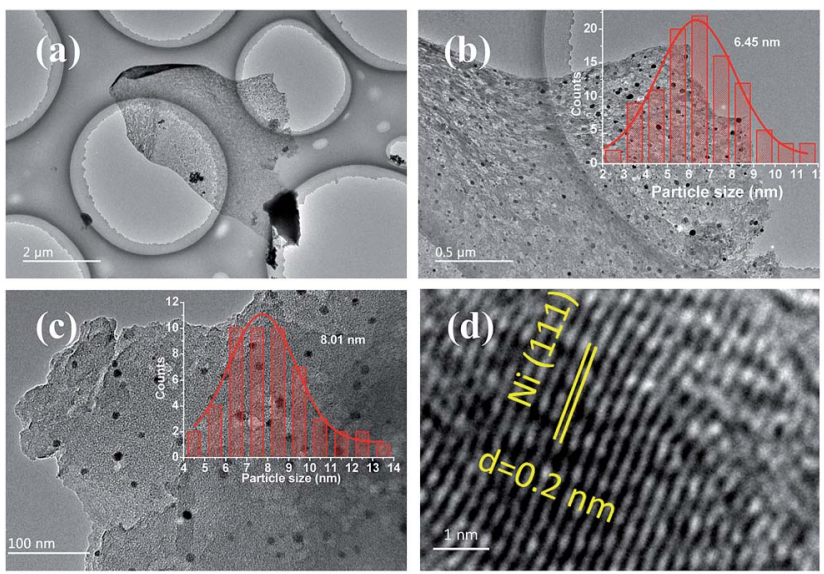

Fig. 3 TEM images and size distribution histograms of ( $a$ and $b)$ CNFs$\mathrm{Ni}$, (c) CFs-Ni, and (d) HR-TEM image of CNFs-Ni.
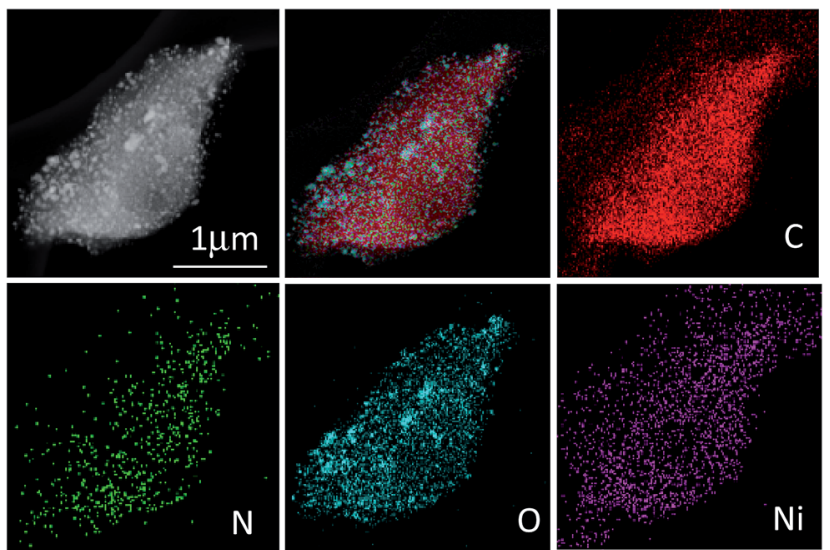

Fig. 4 STEM image and EDX mappings of CNFs-Ni.

CNFs-Ni composites. The broad strong diffraction peak around $23.8^{\circ}$ is likely due to the presence of graphite carbon, while peaks at $2 \theta=44.5,51.8$, and $76.3^{\circ}$ correspond to Ni (111), (200), and (220) planes, respectively. No diffraction peaks corresponding to nickel oxide are observed which might due to the relative low content of the oxide layer at the catalysts surface which can be identified by XPS characterization. And the average crystallite sizes for CNFs-Ni and CFs-Ni catalysts were calculated using the Scherrer formula ${ }^{29}$ as 6.7 and $8.2 \mathrm{~nm}$, respectively, based on the (111) diffraction peak. The nanoparticles highly dispersed on supports surfaces and no aggregates formed during the pyrolysis process indicating the strong anchoring effect of the supporting material. The above particle sizes were similar to those obtained by TEM characterisation.

In order to study the surface electronic properties, the surface chemical states of the catalysts were investigated by XPS. The Ni 2p spectra of the composites are shown in Fig. 5a and $b$. Arising from the multi-electron excitation, broad satellite peaks along with the main peaks were observed in Ni 2 p core-
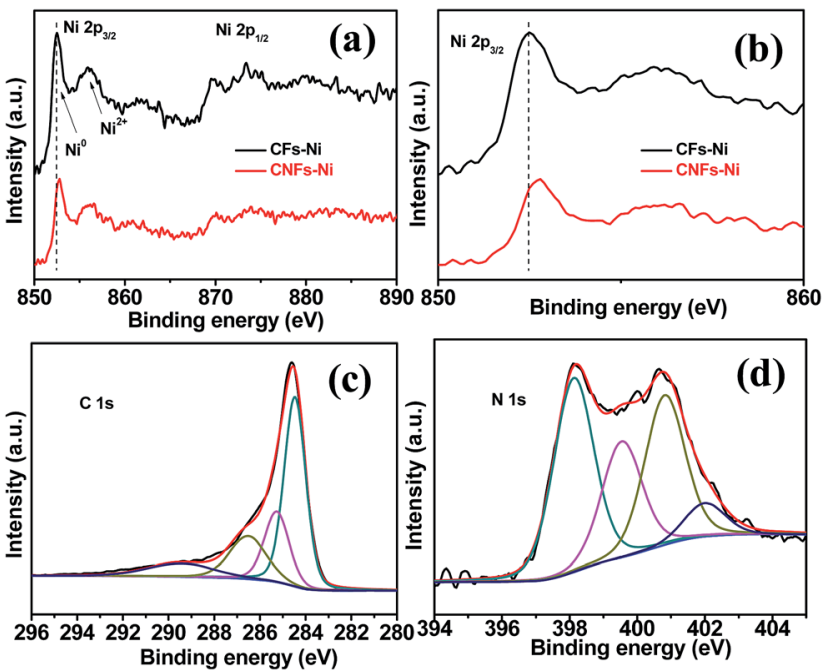

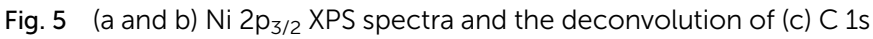
and (d) $\mathrm{N}$ 1s spectra for CNFs-Ni. 
level spectra. ${ }^{19}$ In addition to the shake-up satellite peaks, the $\mathrm{Ni}$ $2 \mathrm{p}$ peaks around $852.7\left(2 \mathrm{p}_{3 / 2}\right)$ and $869.8 \mathrm{eV}\left(2 \mathrm{p}_{1 / 2}\right)$ originate from metallic $\mathrm{Ni}$. In addition, the $\mathrm{Ni} 2 \mathrm{p}_{3 / 2}$ peak around $855.8 \mathrm{eV}$ and the $\mathrm{Ni} 2 \mathrm{p}_{1 / 2}$ peak around $873.5 \mathrm{eV}$ indicate the presence of $\mathrm{Ni}^{2+}$ on the catalysts surfaces. ${ }^{30,31}$ Compared to those of CFs-Ni, the Ni 2p peaks of CNFs-Ni (Fig. 5b) are significantly shifted (about $0.3 \mathrm{eV}$ ) to higher binding energies which might be attributed to the interaction between $\mathrm{Ni}$ and CNFs, resulting in decreased electron density for Ni. The C 1s XPS spectrum of CNFs-Ni in Fig. 5c can be deconvoluted into four peaks: C1 (284.6 eV, C-C), C2 (285.3 eV, C=N), C3 (286.6 eV, C-N), and C4 (289.6 eV, O-C=O). ${ }^{31,32}$ Fig. $5 \mathrm{~d}$ shows that the $\mathrm{N}$ 1s XPS spectrum of CNFs-Ni can also be deconvoluted into four peaks: N1 (398.1 eV, pyridinic N), N2 (399.5 eV, pyrrolic N), N3 $(400.8 \mathrm{eV}$, graphitic $\mathrm{N})$, and $\mathrm{N} 4\left(402.0 \mathrm{eV}\right.$, nitrogen oxides). ${ }^{33,34}$ The $\mathrm{N}$ content is 1.89 at\% by XPS characterization.

\section{Activity of catalysts in methanol oxidation}

Cyclic voltammetry (CV) was used to investigate the electrocatalytic activity of the catalysts. As shown in Fig. 6a and b, a pair of redox peaks corresponding to $\mathrm{Ni}(\mathrm{II}) / \mathrm{Ni}(\mathrm{III})$ redox reaction were found. Furthermore, the cyclic voltammograms demonstrated the peak current increased with the scan rate, and the peak current present a linear relationship with the square root of the scan rate, in addition, the anodic peak potentials and cathodic peak potentials shift to more positive and negative potentials, respectively, thus, the transformation of $\mathrm{Ni}(\mathrm{OH})_{2}$ to $\mathrm{NiOOH}$ of the catalyst is a diffusion controlled process. The insets in Fig. $6 \mathrm{a}$ and $\mathrm{b}$ present the relative diffusion velocity of both catalysts. As shown in the insets, the slopes for CNFs-Ni and CFs-Ni are 0.0075 and 0.0044 , respectively. The larger slope related to better diffusion properties, so that more electroactive NiOOH species formed on CNFs-Ni catalyst. ${ }^{35}$ The electrocatalytic oxidation of methanol by $\mathrm{NiOOH}$ is enabled by the unpaired d-electrons or empty d-orbitals of $\mathrm{NiOOH}$, which
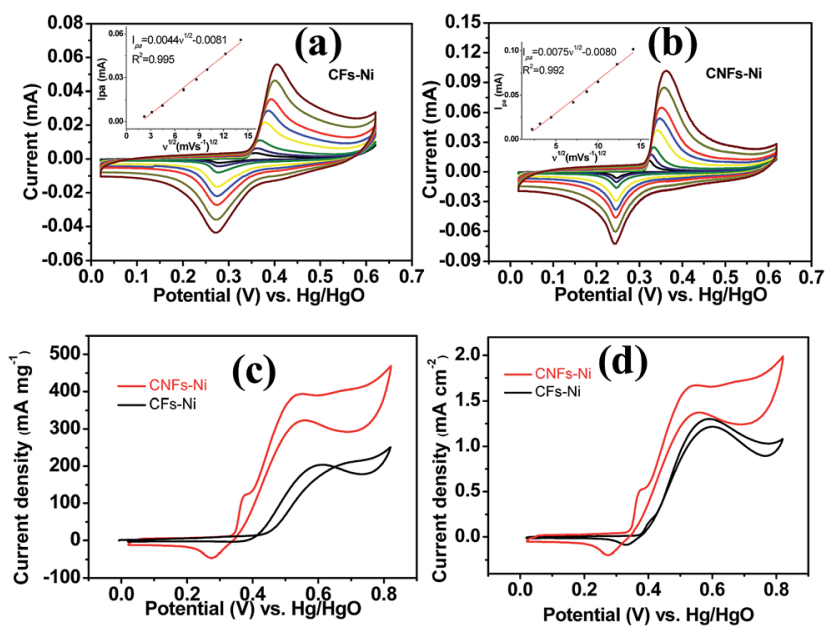

Fig. 6 Linear relationship between the CV anodic peak current in $1.0 \mathrm{M} \mathrm{KOH}\left(I_{\mathrm{pa}}\right)$ and the square root of the scan rate $\left(\nu^{1 / 2}\right)$ for (a) CFs-Ni and (b) CNFs-Ni. (c) Mass activities and (d) specific activities of CFs-Ni and CNFs- $\mathrm{Ni}$ in $1.0 \mathrm{M} \mathrm{KOH} / 0.5 \mathrm{M} \mathrm{CH}_{3} \mathrm{OH}$ (scan rate $50 \mathrm{mV} \mathrm{s}^{-1}$ ). are available for bond formation with absorbed species or redox intermediates. $^{36,37}$ The mechanism of the electro-oxidation of methanol over $\mathrm{Ni}$ is shown below: ${ }^{38}$

$$
\begin{gathered}
\mathrm{Ni}+2 \mathrm{OH}^{-}-2 \mathrm{e}^{-} \rightarrow \mathrm{Ni}(\mathrm{OH})_{2} \\
\mathrm{Ni}(\mathrm{OH})_{2}+\mathrm{OH}^{-}-\mathrm{e}^{-} \rightarrow \mathrm{NiOOH}+\mathrm{H}_{2} \mathrm{O} \\
\mathrm{NiOOH}+\mathrm{CH}_{3} \mathrm{OH} \rightarrow \\
\mathrm{Ni}(\mathrm{OH})_{2}+\text { products }\left(\mathrm{HCOO}^{-} \text {or } \mathrm{CO}_{3}{ }^{2-}\right)
\end{gathered}
$$

It is worth mentioning that prior to the electrocatalytic activity tests, all catalysts were conditioned by potential cycling over 200 times at a scan rate of $50 \mathrm{mV} \mathrm{s}^{-1}$ in $1 \mathrm{M} \mathrm{KOH}$, which was necessary to enrich the catalyst surface with hydroxides and oxyhydroxides, resulting in the thickening of electrocatalytic layers. Fig. $6 \mathrm{c}$ shows the mass activity of the samples, normalised to the Ni mass on the GC electrode. The catalyst mass loadings determined by ICP tests equal 3.27 and 3.32\% for CNFs-Ni and CFs-Ni, respectively. The mass activity of CNFs-Ni at the peak potential can reach $400 \mathrm{~mA} \mathrm{mg}^{-1}$, exceeding that of CFs-Ni (298 $\mathrm{mA} \mathrm{mg}{ }^{-1}$ ) 1.3-fold. More importantly, the onset potential of CNFs-Ni is negatively shifted by about $40 \mathrm{mV}$ vs. $\mathrm{Hg} / \mathrm{HgO}$ compared to that of CFs-Ni. The main oxidation peak of CNFs$\mathrm{Ni}$ is located around $526 \mathrm{mV}$ vs. $\mathrm{Hg} / \mathrm{HgO}$, while that of CFs-Ni was around $582 \mathrm{mV}$. The evident negative shift of peak and onset potentials demonstrates that nitrogen doping makes the catalyst more kinetically effective for methanol oxidation. For both catalysts, a small peak could be found before the main methanol oxidation peak, indicating that the electrocatalytic oxidation reaction of $\mathrm{Ni}(\mathrm{OH})_{2}$ occurs before methanol oxidation.

The good catalytic performance of CNFs-Ni catalyst arises from the nitrogen doped carbon frameworks which provide anchoring sites for active nickel nanoparticles, active sites and charge transfer channel for catalytic reactions. And the electronic effect caused by the incorporation of nitrogen atoms also contributes to the improved activity. Fig. 6d also shows the specific activity curves of the samples, normalised to the geometric surface area of the GC electrode. In this study, the methanol oxidation current barely increased at methanol concentrations above $0.9 \mathrm{M}$ (Fig. 7a), which is caused by the reason that when the methanol concentration is up to relatively high, the methanol oxidation reaction is not controlled by the
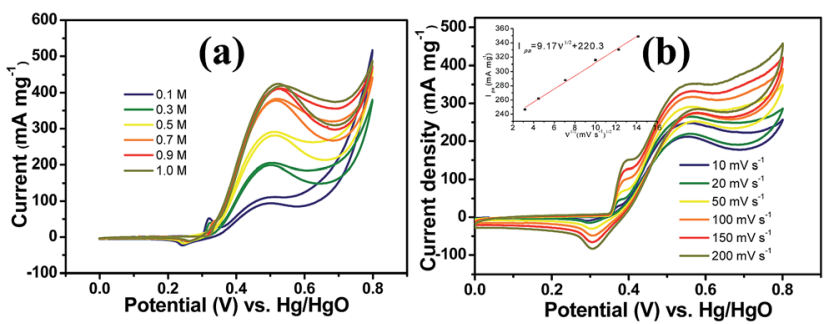

Fig. 7 (a) Methanol oxidation current response of CNFs-Ni with increasing methanol concentration (scan rate $20 \mathrm{mV} \mathrm{s}^{-1}$ ) and (b) methanol oxidation current response of CNFs-Ni with increasing scan rate in $1.0 \mathrm{M} \mathrm{KOH} / 0.5 \mathrm{M} \mathrm{CH}_{3} \mathrm{OH}$. 
diffusion of methanol molecules to the catalyst/electrolyte interface, but the direct reaction of methanol and catalyst occurred. This is also reported for another Ni-based catalyst. ${ }^{39}$ When the methanol concentration is relatively lower, as shown in Fig. 7b, the methanol oxidation current changed with increasing scan rate, and the inset in Fig. $7 \mathrm{~b}$ demonstrates the plot of linear relation between peak current and square root of the scan rate demonstrating that the oxidation reaction is a methanol diffusion-controlled reaction. Fig. S2 $\uparrow$ shows the Nyquist plots of CFs-Ni and CNFs-Ni measured at an open circuit potential ( $v s$. $\mathrm{Hg} / \mathrm{HgO}$ ) in the frequency range from $10 \mathrm{mHz}$ to $100 \mathrm{kHz}$ by electrochemical impedance spectroscopy (EIS) in $0.5 \mathrm{M} \mathrm{CH}_{3} \mathrm{OH} /$ 1.0 M KOH solution. Nyquist plots were fitted by the software EClab, and the inset is the equivalent electrical circuit used to fit the EIS data $\left(C_{\mathrm{dl}}, R_{\mathrm{S}}, R_{\mathrm{SEI}}\right.$ and $R_{\mathrm{ct}}$ are the double layer capacitance, electrolyte resistance, electrode/electrolyte interface resistance and charge-transfer resistance respectively). The impedance parameters of CFs-Ni and CNFs-Ni catalysts are listed in Table S1. $\dagger$ It can be observed that, both the charge transfer resistance and especially, the interface resistance decreased after nitrogen doping. The depressed arc radius in the high-frequency region of the Nyquist plot corresponds to the electron transfer limited process. ${ }^{40}$ After nitrogen doping, the arc radius was reduced, and revealing decreased interface impedance and accelerated electron transfer. This is related to the fact that after nitrogen doping, the Fermi level of carbon shift closer to the conduction band due to the extra electron of nitrogen, thus, the carbon matrix becoming more conductive. ${ }^{\mathbf{4 1 , 4 2}}$ Chronoamperometric tests were conducted to assess the electrocatalytic stabilities of the catalysts. Fig. 8a displays the corresponding curves recorded in $0.5 \mathrm{M}$ $\mathrm{CH}_{3} \mathrm{OH} / 1.0 \mathrm{M} \mathrm{KOH}$ at $526 \mathrm{mV}$ vs. $\mathrm{Hg} / \mathrm{HgO}$. At $3600 \mathrm{~s}$, the mass activity of CNFs-Ni (395.5 mA mg $\left.{ }^{-1}\right)$ is still higher than that of CFs-Ni, with no evident activity loss observed with time. The long-term stability was also tested by recording CV curves in $0.5 \mathrm{M} \mathrm{CH}_{3} \mathrm{OH} / 1.0 \mathrm{M} \mathrm{KOH}$ for up to 300 consecutive cycles (Fig. 8b and c). For CNFs-Ni, the current remained almost stable from the
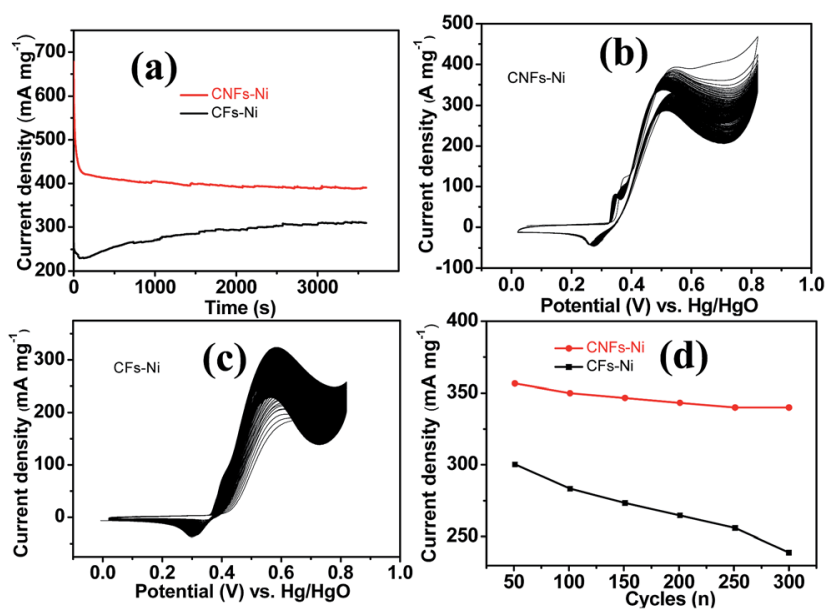

Fig. 8 (a) Chronoamperometric study of CFs-Ni and CNFs-Ni at a constant potential of $5.26 \mathrm{~V}$ vs. $\mathrm{Hg} / \mathrm{HgO}$. ( $\mathrm{b}$ and c) $\mathrm{CV}$ curves of catalysts in $1.0 \mathrm{M} \mathrm{KOH} / 0.5 \mathrm{M} \mathrm{CH}_{3} \mathrm{OH}$ for 300 cycles (scan rate $50 \mathrm{mV}$ $\mathrm{s}^{-1}$ ) and (d) the corresponding change in peak current density. $50^{\text {th }}$ to the $300^{\text {th }}$ cycle; however, the current density for CFs-Ni clearly decreased compared to the initial value (Fig. 8d). Thus, the cycling durability test revealed that the stability of the CFs-Ni catalyst can be greatly enhanced by nitrogen doping. Due to the similar atom size of nitrogen and carbon, the strong delocalized bond formed due to the incorporation of nitrogen atoms which improves the stability. ${ }^{\mathbf{4}}$ And the enhanced stability might also be confirmed by the strong binding of metal atoms and nitrogen doping supports. ${ }^{\mathbf{4 4 , 4 5}}$

The three dimensional carbon frameworks not only provide anchoring sites for active nickel particles but also the effective channel for ions and charges transfer which lead to the acceleration of electrocatalytic reaction. However, both the CNFs-Ni and CFs-Ni catalysts have the same three dimensional structures due to the similar preparation processes, the good electrocatalytic activity cannot be attributed to the structure of the support alone. The nitrogen atoms doping into the carbon layers facilitates the reactivity of the neighbourly located carbon atoms might also contributed to the enhanced electrocatalytic activity. ${ }^{46}$ It is reported that pyridinic and pyrrolic nitrogen atoms resulted in the disordered structure. It is generally considered that supportprecursor interactions inevitably affect the morphology, particle size and distribution, and the defects located at the edge of graphene layers, thus, more nucleation sites for nanoparticle attach generated. ${ }^{47}$ In our case, from the XPS results, the pyridinic and pyrrolic nitrogen accounts for more than $60 \%$ of the all nitrogen containing species, and this might contribute to the enhanced activity of catalysts. In this study, the N-containing surface functionalities of CNFs were identified by XPS, and when nickel nanoparticles interact with CNFs, nickel would donate electrons to CNFs resulting in the decreased electrons density of nickel nanoparticles in CNFs-Ni. The lower electrons density of nickel resulted in weaker adsorption of reaction intermediates on catalysts surface, so the surface coverage of intermediates reduced which might also affect the activity and stability. In addition, the incorporation of nitrogen atoms not only influenced the electronic structure of carbon materials, but also affected the charge transfer properties at the electrolyte/ catalyst interface. EIS measurements reveal that nitrogen doping decreased the interface impedance and accelerated the electron transfer, enhancing the catalytic properties.

Hydrolysis was performed after the coordination of metal ions to crystallise the precursors that nucleate and form nanocrystals. $^{48}$ During thermal treatment, the reduction of nickelcontaining species into larger particles or aggregates via Ostwald ripening was impeded due to their interaction with CNFs. From the TEM characterization, after nitrogen doping, the average particle size of CNFs-Ni $(6.45 \mathrm{~nm})$ is smaller than that of CFs-Ni (8.01 nm), and better dispersion can also obtained. Smaller particle size and better dispersion of nickel nanoparticles also contributed to the improved activity.

\section{Conclusions}

In summary, an effective CNFs-Ni catalyst with enhanced catalytic activity and stability was developed. We used a simple, productive method to synthesis nitrogen-doped carbon 
frameworks with honeycomb-like porous structure. This catalyst showed excellent stability compared to its non-doped counterpart. The excellent electrochemical performance of this composite is attributed to its continuous honeycomb-like network with ultrathin walls doped with nitrogen, which facilitates the uniform distribution and anchoring of $\mathrm{Ni}$ nanoparticles. We proposed that the decreased interface and charge transfer impedance, uniform dispersion and smaller size of the active nanoparticles, and interactions between the supporting CNFs and Ni nanoparticles which leaded to lower electrons density of nickel and weaker adsorption of reaction intermediates contribute to the improved electrocatalytic performance.

\section{Acknowledgements}

This work was supported by the Science and Technology Commission of Shanghai Municipality (No. 14DZ2261000).

\section{References}

1 Y. Zheng, Y. Jiao, L. H. Li, T. Xing, Y. Chen, M. Jaroniec and S. Z. Qiao, ACS Nano, 2014, 8, 5290-5296.

2 W. Qi and D. S. Su, ACS Catal., 2014, 4, 3212-3218.

3 M. S. Risbud, S. Baxter and M. Skyllas-Kazacos, Open Fuels Energy Sci. J., 2012, 5, 9-20.

4 Y. S. Wang, S. Y. Yang, S. M. Li, H. W. Tien, S. T. Hsiao, W. H. Liao, C. H. Liu, K. H. Chang, C. C. M. Ma and C. C. Hu, Electrochim. Acta, 2013, 87, 261-269.

5 N. Jha, R. I. Jafri, N. Rajalakshmi and S. Ramaprabhu, Int. J. Hydrogen Energy, 2011, 36, 7284.

6 M. Gong, W. Zhou, M. C. Tsai, J. G. Zhou, M. Y. Guan, M. C. Lin, B. Zhang, Y. F. Hu, D. Y. Wang, J. Yang, S. J. Pennycook, B. J. Hwang and H. J. Dai, Nature, 2016, 5, 4695.

7 S. B. Wang, Y. A. Xing, H. Z. Xu and S. C. Zhang, ACS Appl. Mater. Interfaces, 2014, 6, 12713-12718.

8 J. Li, Q. L. Zhu and Q. Xu, Chem. Commun., 2015, 51, 1082710830.

9 S. Dommele and K. P. áde Jong, Chem. Commun., 2016, 46, 4859-4861.

10 S. Maldonado and K. J. Stevenson, J. Phys. Chem. B, 2005, 109, 4707-4716.

11 Z. H. Sheng, L. Shao, J. J. Chen and W. J. Bao, ACS Nano, 2011, 5, 4350-4358.

12 K. N. Wood, R. O. Hayre and S. Pylypenko, Energy Environ. Sci., 2014, 7, 1212-1249.

13 Y. Liang, J. Wei, X. Y. Zhang, J. Zhang, S. P. Jiang and H. T. Wang, ChemCatChem, 2016, 8, 1901-1904.

14 X. Xu, Y. Li, Y. T. Gong, P. F. Zhang, H. R. Li and Y. Wang, J. Am. Chem. Soc., 2012, 134, 16987-16990.

15 L. D. Shao, X. Huang and D. Teschner, ACS Catal., 2014, 4, 2369-2373.

16 H. He, P. Xiao, M. Zhou, Y. H. Zhang, Q. Lou and X. Dong, Int. J. Hydrogen Energy, 2012, 37, 4967-4973.

17 L. R. Zhang, J. Zhao, M. Li, H. T. Ni, J. L. Zhang, X. M. Feng, Y. W. Ma, Q. L. Fan, X. Z. Wang, Z. Hu and W. Huang, New J. Chem., 2012, 36, 1108-1113.
18 P. R. Jothi, S. Kannan and G. Velayutham, J. Power Sources, 2015, 277, 350-359.

19 J. B. Wu, Z. G. Li, X. H. Huang and Y. Lin, J. Power Sources, 2013, 224, 1-5.

20 H. S. Hou, G. E. Banks, M. J. Jing, Y. Zhang and X. B. Ji, Adv. Mater., 2015, 16, 7861-7866.

21 X. Zhao, H. Zhao, T. Zhang, X. Yan, Y. Yuan, H. H. Zhao, D. Zhang, G. Zhu and X. Yao, J. Mater. Chem. A, 2014, 2, 11666-11671.

22 J. Y. Choi, R. S. Hsu and Z. Chen, J. Phys. Chem. C, 2010, 114, 8048-8053.

23 Y. He, X. Han, Y. Du, B. Song, P. Xu and B. Zhang, ACS Appl. Mater. Interfaces, 2015, 8, 3601-3608.

24 N. Daems, X. Sheng, I. F. J. Vankelecom and P. P. Pescarmona, J. Mater. Chem. A, 2014, 2, 4085-4110.

25 N. Gavrilov, I. A. Pašti, M. Mitrić, J. Travas-Sejdić, G. ĆirićMarjanović and S. V. Mentus, J. Power Sources, 2012, 220, 306-316.

26 Y. L. Liu, C. X. Shi, X. Y. Xu, P. C. Sun and T. H. Chen, J. Power Sources, 2015, 283, 389-396.

27 Y. G. Chen, J. J. Wang, H. Liu, M. N. Banis, R. Y. Li, X. L. Sun, T. K. Sham, S. Y. Ye and S. N. Knights, J. Phys. Chem. C, 2011, 115, 3769-3776.

28 Y. Zhou, R. Pasquarelli, T. Holme, J. Berry, D. Ginleyc and R. O'Hayre, J. Mater. Chem., 2009, 19, 7830-7838.

29 S. N. Anitha and I. Jayakumari, J. Nanosci. Nanotechnol., 2015, 1, 26-31.

30 L. L. Wang, D. F. Zhang and L. Guo, Nanoscale, 2014, 6, 46354641.

31 Y. S. Li and Y. L. He, RSC Adv., 2014, 4, 16879-16884.

32 Y. L. Huang, H. W. Tien, C. C. M. Ma, S. Y. Yang, S. Y. Wu, H. Y. Liu and Y. W. Mai, J. Mater. Chem., 2011, 21, 1823618241.

33 A. P. Dementjev, A. D. Graaf, M. C. M. V. D. Sanden, K. I. Maslakov, A. V. Naumkin and A. A. Serov, Diamond Relat. Mater., 2000, 9, 1904-1907.

34 Z. H. Sheng, L. Shao, J. J. Chen, W. J. Bao, F. B. Wang and X. H. Xia, ACS Nano, 2011, 5, 4350-4358.

35 M. S. Kim, T. S. Hwang and K. B. Kim, J. Electrochem. Soc., 1997, 144, 1537-1543.

36 M. Vidotti, C. D. Cerri, R. F. Carvalhal, J. C. Dias, R. K. Mendes, S. I. Córdoba de Torresi and L. T. Kubota, J. Electroanal. Chem., 2009, 636, 18-23.

37 L. A. Hutton, M. Vidotti, A. N. Patel, M. E. Newton, P. R. Uniwin and J. V. Macpherson, J. Phys. Chem. C, 2011, 115, 1649-1658.

38 W. Huang, Z. L. Li, Y. D. Peng, S. Chen, J. F. Zheng and Z. J. Liu, J. Solid State Electrochem., 2005, 9, 284-289.

39 S. Xie, X. L. Tong, G. Q. Jin, Y. Qin and X. Y. Guo, J. Mater. Chem. A, 2013, 1, 2104-2109.

40 W. Sugimoto, H. Iwata, K. Yokoshima, Y. Murakami and Y. Takasu, J. Phys. Chem. B, 2005, 109, 7330-7338.

41 J. Duan, S. Chen, M. Jaroniec and S. Z. Qiao, ACS Catal., 2015, 5, 5207-5234.

42 S. Maldonado, S. Morin and K. J. Stevenson, Carbon, 2006, 44, 1429-1437. 
43 H. Kim, K. Lee, S. I. Woo and Y. Jung, Phys. Chem. Chem. Phys., 2011, 13, 17505-17510.

44 Y. H. Li, T. H. Hung and C. W. Chen, Carbon, 2009, 47, 850.

45 W. An and C. H. Turner, J. Phys. Chem. C, 2009, 113, 70697078.
46 C. H. Wang, H. Y. Du, Y. T. Tsai, C. P. Chen, C. J. Huang, L. C. Chen, K. H. Chen and H. C. Shih, J. Power Sources, 2007, 171, 55-62.

47 R. L. Jia, C. Y. Wang and S. M. Wang, J. Mater. Sci., 2006, 41, 6881-6888.

48 Z. L. Xin, J. Wang, X. Huang, Y. Y. Yao and L. D. Shao, J. Electrochem. Soc., 2015, 162, H898-H902. 